\title{
COMMON PERONEAL NEUROPATHY AFTER LITHOTOMY POSITION AND ITS TREATMENT MODALITIES
}

Shrinivas Kulkarni1 ${ }^{1}$, Sneha G. S2

\section{HOW TO CITE THIS ARTICLE:}

Shrinivas Kulkarni, Sneha G. S. "Common Peroneal Neuropathy after Lithotomy Position and its Treatment Modalities". Journal of Evolution of Medical and Dental Sciences 2015; Vol. 4, Issue 51, June 25;

Page: 8944-8946, DOI: 10.14260/jemds/2015/1296

ABSTRACT: INTRODUCTION: Prolonged lithotomic position has been blamed for common peroneal neuropathy and transient neurological symptoms related to pressure and compression. Here we have discussed about recognition, treatment and prevention. CASE REPORT: A 45 year old female with normal pre anaesthetic evaluation underwent elective mayo wards hysterectomy under spinal anaesthesia with Inj. Bupivacaine (hyperbaric) 2.2cc+Inj. Fentanyl (25mcg). Intra operative course was uneventful. Patient was haemodynamically stable. Surgery lasted for 3 hours. The next day of surgery started ambulating she complained of difficulty to walk without support and weakness in both lower limbs, not associated with pain. Neurological examination showed bilateral weakness in dorsiflexion and sluggish ankle jerk. X ray and MRI, LS spine was normal. Nerve conduction study showed decreased conduction in bilateral common peroneal nerves. She was treated with steroids and hydroxy methyl cobalamin and physiotherapy. She was discharged with complete recovery on $15^{\text {th }}$ post-operative day. DISCUSSION: Bilateral weakness of lower limbs due to lithotomic position under spinal is a well-documented complication. Possibility of direct trauma to peripheral nerve or spinal cord trauma should be ruled out. Risk factors include duration of lithotomic position $>3$ hours, BMI <20. Compression of common peroneal nerve at head of fibula due to direct pressure of metal rod causes neuropathy. We recommend preventing nerve compression by using soft cotton padding between metal rod and leg to decrease the pressure on common peroneal nerve. CONCLUSION: Peripheral nerve injuries are a complication of anaesthesia related to position and operative procedure, which is accounted for medico legal claims and difficult to defend. Early recognition, investigation and treatment can prevent this complication.

KEYWORDS: Lithotomy position, Common peroneal nerve injury, Subarachnoid block.

INTRODUCTION: Prolonged lithotomy position under spinal anaesthesia has been blamed for common peroneal neuropathy, transient neuropathy and transient neurological symptoms. ${ }^{1,2}$ Here it was necessary to exclude nerve injury which might have been due to spinal anaesthesia. Many publications have been done about common peroneal nerve injury. Here we have discussed about prevention and treatment. Hence we are reporting this case.

CASE REPORT: A 45 year old female presented with $3^{\text {rd }}$ degree UV prolapse with cystocele since 6 months. Her preoperative history and examination were within normal limits. All her routine investigations were normal. The patient was posted for elective mayo wards hysterectomy under regional anaesthesia. After starting an iv line and preloading with ringer lactate, under strict asepsis, lumbar puncture was done at L3-4 inter space using 23G quinkes spinal needle. After confirming free and clear flow of CSF, Inj. Bupivacaine 0.5\% (Hyperbaric) 2.2cc+ Inj Fentanyl (25mcg) injected intrathecally. Sensory level of T6 was achieved and patient was put into lithotomy position. Intra 


\section{CASE REPORT}

operative course was uneventful and patient was haemodynamically stable throughout. Surgery lasted for 3 hours. At the end of surgery, patient had sensory level up to T12. Six hours after surgery, patient was able to move both lower limbs on bed. After she started ambulating, the next day of surgery, she complained of weakness of both lower limbs and difficulty to walk without support. She had no complaints of radiating pain in limbs or bladder and bowel dysfunction. Neurological examination showed bilateral weakness in dorsiflexion and sluggish ankle jerk. X ray and MRI of lumbo sacral spine were normal. Nerve conduction study was done which showed decreased conduction in bilateral common peroneal nerve, more on right side.

Her serum electrolytes were within normal limits. In the meantime she was treated with steroids. Tab Prednisolone 5mg initially tapered over two weeks and stopped. She was given Inj hydroxyl methyl cobalamin for two weeks. She was discharged on $15^{\text {th }}$ post operative day with complete recovery.

DISCUSSION: Bilateral weakness of lower limbs due to lithotomy position under regional anaesthesia is a well-documented complication. The various possibilities include spinal cord trauma, epidural hematomas/abscess, cauda-equina syndrome, transient neurological symptoms. Risk factors for development of persistent neuropathy include diabetes mellitus, polyarteritisnodosa, leprosy, and other immunological disorders. Duration of surgery $>3$ hours with BMI $<20$ are at risk of neuropathies. ${ }^{3}$ After ruling out all other factors in our patient, we found longer duration of procedure leading to compression of common peroneal nerve as the suspected cause. Lithotomy position mainly used for vaginal hysterectomy has been found responsible for common peroneal neuropathy where there will be compression of common peroneal nerve at the head of fibula due to direct pressure by the metal stand. 4,5 We have done all the investigations like X ray, MRI LS spine, NCS to know the etiological factor and found out that nerve conduction in common peroneal nerve was affected in this patient. We recommend soft cotton/rubber padding to be used in between metal rod and leg with wide angulations' to create more gap which can prevent nerve compression. ${ }^{6}$ Always it should be made mandatory to check the motor and sensory components after wear off of regional anaesthesia. Treatment after recognition of neuropathy should be with steroids, hydroxyl methyl cobalamin and physiotherapy, which gives excellent results within 15 days.

CONCLUSION: Peripheral nerve lesions are a complication of regional anaesthesia, related to position and operative procedures, which is accounted for medico legal claims and difficult to defend. Prevention, investigation and proper treatment can prevent this complication.

\section{REFERENCES:}

1. Dr. Ruchigupta, Dr. Veena Valecha, Dr. Walia S.S. Femoral neuropathy after lithotomy position-its treatment modalities. IJA: 2006; 50(2): 143-144.

2. Venkariya RD. Persistent lower limb weakness following spinal anaesthesia-two case reports. Jan aesth clin parmacol 2004; 20(2): 179-82.

3. Warner MA. Lower extremity motor neuropathy associated with surgery performed on patients in a lithotomy position.Anaesthesiology1994; 81(1):

4. R. J. Sawyer, MN Richmond, J. D Hickey and J. A. Jarrratt-Anaesthesia, 2000, 55, 980-991.

5. Garland H, Moorhouse D. Compressive lesions of the external popliteal (Common peroneal) nerve. British Medical Journal 1952; 2: 1373-8. 


\section{CASE REPORT}

6. Practice advisory for the prevention of perioperative peripheral neuropathies. A report by American society of Anaesthesiologists task force on prevention of perioperative peripheral neuropathies. Anaesthesiology 2000; 92: 1168-82.

\section{AUTHORS:}

1. Shrinivas Kulkarni

2. Sneha G. S.

\section{PARTICULARS OF CONTRIBUTORS:}

1. Assistant Professor, Department of Anaesthesiology, MMC \& RI, Mysore.

2. Post Graduate Student, Department of Anaesthesiology, MMC \& RI, Mysore.

FINANCIAL OR OTHER

COMPETING INTERESTS: None

\section{NAME ADDRESS EMAIL ID OF THE} CORRESPONDING AUTHOR:

Dr. Shrinivas Kulkarni, \# 4, Lakshmi Nivas,

Preethi Layout, Srirampura $3^{\text {rd }}$ stage, Mysore-570023.

E-mail: drsrikulkarni@gmail.com

Date of Submission: 02/06/2015. Date of Peer Review: 03/06/2015. Date of Acceptance: 18/06/2015. Date of Publishing: 25/06/2015. 